\title{
APROXIMACIÓN A LOS CUENTOS DE CHARLES NODIER
}

\section{Giovanna Armellin Secchi}

\begin{abstract}
RESUMEN
El propósito de este artículo es contribuir al conocimiento de Charles Nodier (17801844), un escritor francés poco conocido en la actualidad. Presentamos un breve estudio acerca de los cuentos escritos por este autor entre 1830 y 1840 , una década en que Nodier produjo abundantes trabajos narrativos relacionados con el tema del sueño.
\end{abstract}

\begin{abstract}
The purpose of this article is to contribute to the knowledge of Charles Nodier (17801844), a French writer who is not yet well known. We present a brief study of the short stories written between 1830 and 1840 , a decade in which Nodier produced many narrative works related to the subject of dream.
\end{abstract}

En este estudio se buscará un acercamiento a la cuentística del escritor francés Charles Nodier (1780-1844) desde la perspectiva de uno de sus temas fundamentales: el sueño como detonante de una serie de elementos que conforman la literaturidad de su obra narrativa, utilizando como modelo los cuentos de la década 1830-1840, por tratarse de un período particularmente productivo del escritor. En cambio, los años desde 1822 hasta 1830 están caracterizados por una intensa participación de Nodier en la vida social y por la publicación de muchos artículos, prefacios, ensayos históricos y críticos, que lo alejan mucho de la obra narrativa. El escritor en ese entonces era el huésped generoso del Arsenal, bibliotecario y un brillante animador de la vida mundana del momento. No nos debe maravillar, pues, el hecho de que estos años tan agitados en cuanto a vivencias, resulten estériles en lo que concierne a la producción literaria. Esta coincidencia nos lleva a comprobar, una vez más, la tesis según la cual Nodier encuentra en su producción artística un refugio donde las necesidades de la vida no le afectan o le afectan poco. Este aislamiento resulta necesario cuando las situaciones concretas, la realidad, se hacen difíciles y hasta inaceptables, o bien cuando los acontecimientos exteriores son tan dolorosos que se vuelven increíbles y absurdos. He aquí, entonces, que a lo absurdo de la vida Nodier, lo sustituye por la lógica del sueño: "non seulement l'état le plus puissant, mais encore le plus lucide de la pensée" (Nodier 1969: 341). Es decir, sus obras de mayor relieve se generan en el sueño nocturno, que le permite huir de la imitación para así lograr la creación original, tan propia de sus 
cuentos. Esto se debe a que la imaginación, como eje fundamental de la creación artística, interactúa en forma preponderante sobre los sueños. Las imágenes así producidas no sufren la interferencia de las sensaciones externas:

Il peut paraitre extraordinaire, mais il est certain que le sommeil est non seulement l'état le plus puissant, mais encore le plus lucide de la pensée, si non dans les illusions passagères dont il l'enveloppe, du moins dans les perceptions qui en dérivent (Nodier 1832: 160).

De tal suerte, la imaginación como producto del sueño permitiría lograr el máximo nivel de perfección, ya que las sensaciones nuevas que nacen se intensifican en el sueño y no pueden ser transferidas a la vida real: pertenecen al mundo imaginario.

La abundante producción de cuentos que caracteriza el decenio de 1830 a 1840 puede entenderse remontándonos a la crisis profunda que Nodier atraviesa a partir de 1830: las dificultades financieras lo obligan a vender muchos de sus libros, las reuniones en el salón del Arsenal se hacen cada vez menos frecuentes. Por otro lado, su hija María, al casarse, hace esta situación aún más deplorable ya que Nodier se hunde en la soledad y la desesperación, que se compensan con su apasionada y ardiente imaginación.

En este momento, el espíritu ofuscado por las tinieblas de la vida exterior se libera de todos los ligámenes y encuentra su propia esencia en el dulce imperio del sueño, al amparo de todas las influencias de la personalidad convencional que la sociedad le ha impuesto.

En relación con lo anterior, en Nodier, el extraordinario valor del sueño con sus imágenes momentáneas e ilusiones no puede ser reconocido si no se distingue claramente de sus imágenes momentáneas e ilusorias sin valor. En el hecho mismo de soñar, lo que interesa mayormente no son las figuras aparecidas en el sueño, sino la inmensa libertad alcanzada por el espíritu que, superando el límite de su universo habitual, descubre otros espacios. Comunicándose con estos espacios, el espíritu que sueña reconoce lo que es la esencia de sí mismo: es por esto que Nodier compara el sueño con una "mort intermittente".

En cuanto a sus obras, se puede observar cómo desde Une Heure ou la Vision de 1806, pasando por Sept Châteaux du roi de Bohème, Le Songe d'or y Hélène Gillet hasta Inès de las Sierras de 1837, los sueños amorosos renuevan siempre sus imágenes, mientras que en Lydie y en la Neuvaine de la Chandeleur, últimas obras fantásticas de Nodier, el sueño se complica con elementos religiosos, mezclados en el primero de estos cuentos con caricias amorosas y en el segundo con creencias populares.

Si se analiza Trilby, el pasaje de la vida al sueño es tan delicado que con costos se logra distinguir si los deseos de Jeannie y las ternuras del duende pertenecen a uno o a otro mundo. La misma incertidumbre envuelve la culpabilidad de la joven remadora escocesa quien, al descubrir de improviso que los sueños son pecaminosos, se rehúsa a escuchar las advertencias que le sugieren su sentimiento de fidelidad y los sermones del viejo eremita. Este cuento, con la extraordinaria visión de paisajes irreales y de otoños hechizados, esconde bajo tanta belleza el drama aún no resuelto de Nodier: el sentimiento de culpabilidad, el deseo de justificarlo, y la necesidad de no tomar ninguna decisión entre la apología del sueño y la apología de la lúcida moral; esto acompaña toda la composición.

Por otra parte, el cuento "La Fée aux Miettes", diez años más tarde, responde aún mejor a las necesidades de este "fantastique sérieux", que para Nodier consistía en despreciar lo real respetar lo verosímil y lo imposible: 
J'ai dit souvent que Je détestais le vrai dans les arts, et il m'est avis que j'aurais peine à changer d'avis; mais je n'ai jamais porté le même jugement du vraisemblable et du possible, qui me paraissent de première nécéssité dans toutes les compositions de l'esprit (Nodier 1961: 168).

Señala el mismo Nodier que la primera ley de un buen cuento es hacerse creer y para llegar a esto se necesita que nosotros mismos creamos. En ninguna otra composición, Nodier ha observado de manera mejor esta ley. Creía en la fábula que inventaba, porque la hacía por sí mismo, para producir un profundo vuelco en sus sufrimientos personales.

Jules Vodoz ha hecho del cuento "La Fée aux Miettes" una interpretación psicoanalítica llevada, en ciertos puntos, al exceso, en un afán por aclarar aspectos que subyacen en el subconsciente de los personajes (Vodoz 1925).

Por su lado, Auguste Viatte, en su úcfsgltima edición de la obra, en 1962, retoma y amplifica esa interpretación, que será presentada más sistemáticamente y con muchos más detalles por André Lebois (1962).

Pero más allá del significado psicológico, "La Fée aux Miettes" ejerce una fascinación basada en que la obra supera estos datos, transformándolos en manifestaciones auténticas y raras. Los símbolos de esta "féerie" están llenos de pavor frente a la vida erótica y, al mismo tiempo, cargados de deseo de alcanzarla un día de manera perfecta y, por ende, inmaterial. Aquí, el fruto prohibido se manifiesta bajo diferentes apariencias y la esperanza de una casta sensualidad se esconde bajo múltiples máscaras. En sueños, Michel encuentra en la arena "une multitude de jeunes princesses, éblouissantes de charmes et de parure"(Nodier 1961: 215) que se disponen a danzar alrededor de él cantando en una lengua desconocida:

(...) harmonieuse et divine, quoiqu'il me semblât l'entendre par autre sens que celui de l'ouïe, et l'expliquer par une autre faculté que celle de la mémoire (Nodier 1961: 216).

La Fée aux Miettes, como obra completa, es un sueño y un mito, porque todos los elementos aluden simbólicamente a aquellas criaturas que, para Nodier, le hacen amar y temer tanto las alegrías de la vida. Cuando la fascinante vieja que es la Fée aux Miettes, el hada de las migajas, le ofrece a Michel el medallón que, según ella, la fotografiaba de joven, el héroe lo contempla extasiado y la felicidad que él siente es maravillosa porque ve que su vida "se transformer en quelque chose qui n'était plus moi, et qui m'était plus cher que moi" (Nodier 1961: 226). Ya no era más la mujer que él veía y tampoco la divinidad como la había imaginado, era una mujer radiante con una expresión indefinible y cuya vista llenaba el corazón de un gozo más completo y más perfecto que todas las felicidades fantásticas de la imaginación:

Je me taisais ou je laissais à peine échapper quelques exclamations confuses, comme les balbutiements d'un homme endormi qui se croit frappé d'une apparition... (Nodier 1961: 225).

Este es también el deseo de Nodier y de sus criaturas, porque tener conciencia de sí mismo es vivir en el mundo en el cual reinan el error y el castigo, y donde límites precisos y dolorosos frenan la actividad de la imaginación. Así, el sueño se desdobla como el hada misma: Michel, una vez casado con la Fée, forma un matrimonio casto, vive de día cerca de ella, pero cada noche Belkiss, la Fée del medallón, se acerca a él y le ofrece sus caricias. La humilde ca- 
baña se convierte en un palacio lujoso y la joven enamorada que se tira en los brazos de Michel hace callar sus escrúpulos diciendo que ella misma es la Fée aux Miettes:

- La Fée aux Miettes! Repris-je en tressaillant d'un étrange frisson, car tout mon sang s'était réfugié à mon coeur. Belkiss est incapable de me tromper, et cependant je sens que vous êtes presque aussi grande que moi!

- Oh! Que cela ne t'étonne pas, dit-elle, c'est que je me déploie.

- Cette chevelure aux longs anneaux qui flotte sur vos épaules, Belkiss, la Fée aux Miettes ne l'a point!

- Oh! Que cela ne t'étonne pas, dit-elle, c'est que je ne la montre qu'à mon mari.

- Ces deux grandes dents de la Fée aux Miettes, Belkiss, je ne les retrouve pas entre vos lèvres fraîches et parfumées!

- Oh! Que cela ne t'étonne pas, dit-elle, c'est que c'est une parure de luxe qui ne convient qu'à la vieillesse.

- Ce trouble voluptueux, ces délices presque mortelles qui me saississent auprès de vous, Belkiss, je ne les connaissais pas auprès de la Fée aux Miettes!

- Oh! Que cela ne t'étonne pas, dit-elle, c'est que la nuit tous les chats sont gris (Nodier 1961: 316).

A la par de estos sueños que le ofrecen a Michel voluptuosidades perfectas, continúa el otro sueño, en el cual el joven vive a la par de una buena hada: este es el mundo de las prohibiciones, y la amable vieja que el carpintero ama tiernamente desaparece detrás de una puerta cada vez que él quiere acercarse a ella. Aunque ella le asegure al amante que los sueños regresarán todas las noches, que volverá a ver a Belkiss, él permanece inquieto: no entiende todavía la identidad de las dos figuras, hasta el momento en que la Fée se lo dirá. La misma noche, Michel se desliza en la cama de la vieja que lo rechaza. Pero el diálogo del sueño se repite:

- Cette chevelure aux longs anneaux qui flotte sur vos épaules, Fée aux Miettes, vous l'avez jusqu'ici cachée à tous les yeux!

- Oh! Que cela ne t'étonne pas, dit-elle; c'est que je ne voulais la laisser voir qu'à mon mari.

- Ce trouble voluptueux, ces délices presque mortelles qui me saisissent auprès de vous, Fée aux Miettes, je ne les avais éprouvées, avec votre permission que dans les bras de Belkiss!

- Oh! Que cela ne t'étonne pas, dit-elle; c'est que la nuit tous les chats son gris.

- (...) tout est vérité, tout est mensonge (Nodier 1961: 317).

En consecuencia, el matrimonio es consumado: los dos mundos separados finalmente se han reunido. Los dos sueños, el de un universo perfecto y el de los miedos y de las culpas se confunden; la voluptuosidad ya no es alejada en la invención del sueño, está permitida sin ningún sentimiento de culpabilidad en la realidad. Sin duda, la Fée aux Miettes envía a Michel a la búsqueda de la Mandrágora que canta y parece exiliarlo del paraíso recién conquistado. Pero ésta es solamente una prueba momentánea; es necesario que el joven acepte mezclarse con la vida de los hombres y que mantenga intacto su amor; solamente entonces la felicidad no le será rehusada nunca más.

Las últimas páginas del cuento están llenas de ironía con respecto a los hombres de buen sentido, que pretenden explicar todo y que juzgan a Michel como a un loco. Nodier naturalmente está del lado del demente:

(...) créature de rebut ou d'élection, comme vous, ou comme moi, qui vit d'invention, de caprice, de fantaisie et d'amour dans les plus pures régions de l'intelligence, heureux de rapporter de ces champs inconnus quelques fleurs bizarres qui n'ont jamais parfumé la terre (Nodier 1961: 170). 
El loco es, según Nodier, el que ha renunciado a la necesidad de saberlo todo, lo cual constituye el único motivo que nos impide ser felices en esta tierra. Es precisamente en compañía de estos locos como Michel, François y Baptiste, que Nodier trata de olvidar los errores de una civilización cruel y de huir de la obsesión de las ideas que lo persiguen.

"François les Bas-Bleus" es un cuento que se sitúa en la misma línea de "Baptiste Montauban". Los dos héroes son víctimas de un amor que los hará morir, los dos viven en una especie de sueño en donde la razón parece perderse. En Baptiste Montauban, sin embargo, el estado de locura no se acompaña con intuiciones de orden intelectual como en Jean-François "qui est devenu fou à force d'être savant" (Nodier 1961: 366).

Baptiste tiene un poder de comunión con la naturaleza: como San Francisco de Asís, parece dialogar con los pájaros. Esta disposición natural que se une a su rara inocencia del alma, es tal vez la señal de un don celestial, como ocurre con las gracias divinas que iluminan también a Sor Francisca del Santo-Espíritu en Histoire d'Hélène Gillet, una mujer con el espíritu límpido e inocente "aux douces ignorances des enfants".

Sin poseer la amplitud, la riqueza psicológica, la fascinación poética de la Fée aux Miettes, el cuento de Jean-François les Bas-Bleus publicado antes en Cent et une nouvelles de Cent et un, contiene una aguda descripción de la locura. Jean-François, enamorado de una joven noble de la cual lo separan unas profundas diferencias sociales y económicas, herido por la imposibilidad de elevarse hacia ella, se dedica completa y exclusivamente:

(...) à des études périlleuses pour la raison, aux rêves des sciences occultes et aux visions d'un spiritualisme exalté ( Nodier 1961: 374).

Rápidamente se vuelve loco:

(...) un idiot, un monomane, un fou (...) cet oeil que je (Nodier) ne saurais peindre n'était jamais arrêté à l'horizon, mais incessament tourné vers le ciel, avec lequel l'homme dont je vous parle (c'était un visionnaire) paraissait entretenir une comunication cachée, qui ne se faisait connaitre par le mouvement perpétuel de ses lèvres (Nodier 1961: 364).

Jean-François les Bas-Bleus queda desde el inicio hasta el final del cuento como un desadaptado, un marginado de la sociedad que lo considera un pobre de espíritu. Ya en Une Heure ou la Vision, Nodier nos había hablado de un loco, siempre inmóvil y como alejado de la vida que lo rodeaba "assis, les yeux fixés sur un certain point du ciel" (Nodier 1961: 13).

Entonces, Nodier se preguntaba si la locura era la señal de un conocimiento superior de una inteligencia sublime inaccesible para los hombres de buen sentido. Ahora, en 1833, parece querer contestar a esta pregunta y la respuesta es sin duda afirmativa.

Es por esto que "Jean-François les Bas-Bleus", no obstante las evidentes reminiscencias de Louis Lambert de Balzac, queda como uno de los cuentos en que Nodier se ha expresado con más sinceridad. Esta composición debe ser considerada sobre todo, a nuestro parecer, como una brillante ilustración y una lógica consecuencia del desarrollo del pensamiento de Nodier.

Para Nodier, pues, la obra misma constituye un oasis de paz para todas sus inquietudes, una isla en la cual se reconcilia con las imágenes tenebrosas que lo persiguen, haciéndolas partícipes de una "rêverie", de una "féerie" en la cual éstas pierden su poder maléfico. Pero tales imágenes lo pierden solo si se respeta el misterio del cual se rodean. 
El camino seguido por Nodier tiene apenas unas relaciones superficiales con el de sus contemporáneos. Él no sale, como ellos, del miedo ansioso que la criatura siente frente a los acontecimientos de la vida, no busca la "rêverie" que corresponde a la angustiosa metafísica y no llega a la catarsis, a las contemplaciones temporales y sublimes. Él siente ante todo la necesidad de ser protegido en concordancia con la doble vida que se desarrolla dentro de sí.

Es, en fin, pasando a través del sueño, sublimándolo al nivel de poesía, que se llega a aceptar la vida. Lo que le interesa al lector moderno es exactamente este trabajo de reflexión que Nodier ha hecho sobre el sueño, sobre las fuerzas del hombre adormecido, sobre los resortes oscuros y potentes que mueven el inconsciente.

Nodier anuncia el nuevo camino de la investigación literaria, la nueva fuente de inspiración: el sueño. Los sueños seductores de la vida nocturna han inspirado a Nerval, a Victor Hugo, al joven Balzac, a Baudelaire, a los simbolistas, a Lautréamont, a Alain Fournier y a muchos otros más.

También estos escritores estudian las relaciones que se establecen entre las sensaciones de la vida nocturna y las de la vida real. Le dan a este instrumento nuevo la dignidad de un conocimiento privilegiado, superior, capaz de explorar el inconsciente y de lograr la revelación de lo desconocido.

Nodier supo ver, de primero, la importancia de la vida onírica en la creación literaria y le propone a la poesía romántica una nueva consistencia.

Jean-Paul Richer, un crítico contemporáneo, en un estudio sobre Charles Nodier, ha tratado de establecer la filiación entre Nodier y Nerval, subrayando los rasgos que los unen, el amor por ciertas sociedades secretas y por el ocultismo, el gusto por el misterio y por los períodos históricos como el Medioevo, las reflexiones sobre la locura y sobre lo desconocido.

En el Werther de Goethe, Nodier encuentra al hermano espiritual de los personajes de sus novelas, en el Faust, Nerval ve el prototipo de su ideal femenino. El amor y la mujer ofrecen, a estos dos proscritos, el medio para tomar el vuelo hacia el mundo del sueño.

En sus Contes, Nodier es una víctima del amor. Está constantemente en busca de la reina de Saba, tipo legendario por la célebre fascinación femenina, como Nerval en su Voyage en Orient:

\footnotetext{
(...) mon imagination commençait à se former, dans la solitude, un type qui ne ressemblait à aucune femme, et auquel une seule femme devait complètement ressembler, quoique $\mathrm{j}$ 'aie cru le retrouver cent fois. C'était mon rêve chéri, et le vague immense où il m'était apparu; il me donnait une idée plus distincte du bonheur que toutes les réalités de la vie. Cependant je ne faisait que l'entrevoir à travers mille formes douteuses; mais je le cherchais toujours, et le délicieux fantôme ne manquait jamais à mes rêveries. (...) car je savais que toute ma félicité consistait dans la possession de cette image insaisissable (Nodier 1961: 802).
}

Es exactamente por esta pasión del sueño, "idée plus distincte du bonheur que toutes les réalités de la vie", por este gusto de lo fantástico relacionado con todo, que Nodier ha influido más profundamente en el romanticismo y que su presencia es siempre más vivaz y estimulante para los lectores modernos.

De allí la importancia de retomar la obra de este autor francés que ha permanecido casi oculto en la historiografía literaria, para así redescubrir los valores prevalecientes en su escritura. Estos rasgos constituyen una veta inagotable por la suma de elementos estéticos que contienen. 


\section{Bibliografía}

Larat, Jean. 1923. Bibligraphie critique des oeuvres de Charles Nodier. París: Champion.

Lebois, André. 1962. "Un bréviaire du Compagnonnage: La Fée aux Miettes". Archives des Lettres Modernes. N. 40. París: Minard.

Maixner, Robert. 1960. Nodier et l'illirie. París: Didier.

Nodier, Charles. 1832. De quelques Phénomènes du sommeil. París: Renduel.

1832. Souvenirs de jeunesse. París: Levasseur.

1850. Contes fantastiques. París: Charpentier.

1921. Moi-même. París: Champion.

1941. Les milles et une nuits. Contes arabes. París: Garnier.

1944. Trilby. La Fée aux Miettes. París: Skira.

1953. Contes et nouvelles. París: Delmas.

1961. Contes. París: Garnier.

1962. La Fée aux Miettes. Roma: Signorelli.

1969. L'âme romantique et le rêve. París: Corti.

Richer, Jean Paul. 1954. "Nodier et Nerval”. Les cahiers du sud. No. 304.

Viatte, Auguste. 1922. Le Catholicisme chez les Romantiques. París: Boccard.

Vodoz, Jules. 1925. Essai sur le rôle du subconscient dans l'oeuvre de Charles Nodier: La Fée aux Miettes. París: Champion. 
